\title{
Vitamin D3 Supplementation Ameliorates Typical Clinical Symptoms in Children with Autism Spectrum Disorder in Japan: A Case Study
}

Noboru Hasegawa ${ }^{1 *}$, Takako Yamada ${ }^{2}$ and Miyako Mochizuki ${ }^{3}$

${ }^{1}$ Department of Health and Medical Sciences, Ishikawa Prefectural Nursing University, 1-1 Gakuendai, Kahoku, Ishikawa 929-1210, Japan

${ }^{2}$ Department of Occupational Therapy, Bukkyo University, 7, Higashitoganoo-cho, Nishinokyo, Nakagyo-ku, Kyoto604-8418, Japan

${ }^{3}$ Kyoto Bunkyo Junior College, 80 Senzoku, Makishima-cho, Uji, Kyoto 611-0041, Japan

\section{Abstract}

Background: We studied the effects of vitamin D3 supplementation on serum levels of 25-hydroxyvitamin D and typical clinical symptoms in children with autism spectrum disorder (ASD).

Methods: We enrolled 5 male and 1 female Japanese children with ASD aged 3 years. Serum 25-hydroxy

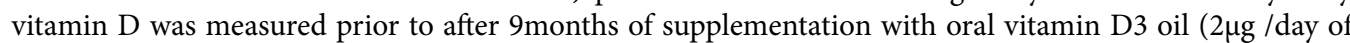
vitamin D3, corresponding to twice the daily requirement). The Childhood Autism Rating Scale (CARS), Short Sensory Profile (SSP), Vineland-II were used to assess the severity of autism-related traits. Data were analyzed using a Wilcoxon test.

Results: The 25-hydroxy vitamin D level were $<20 \mathrm{ng} / \mathrm{mL}$ (deficient) in 2 children, $>=20 \mathrm{ng} / \mathrm{mL}$ and $<$ $30 \mathrm{ng} / \mathrm{mL}$ (insufficient) in 4 children before vitamin D3 supplementation. Our results showed that individual 25 -hydroxy vitamin D levels varied significantly among individuals with supplementation, except in the child whose level was already sufficient. The number of children in the deficient group decreased from 2 to 1 ( 1 : became insufficient), while the number in the insufficient group decreased from 4 to 3 (1: became sufficient). The CARS and SSP scores were decreased in all except in one child who had originally high 25-hydroxy vitamin D levels $(28 \mathrm{ng} / \mathrm{mL})$. Among the children in this study, vitamin D administration showed a positive effect on the "communication skills", "ADL skills", "social skills" or "motor skills" of two of the ASD children assessed with the Vineland-II.

Conclusion: These findings show that vitamin D supplementation might ameliorate typical clinical symptoms in children with autism spectrum disorder.

\section{Introduction}

Autism spectrum disorders (ASD) are developmental disorders associated with a high individual and social burden, but their aetiology is poorly understood. The prevalence of ASD among 3-17 year-old children has suddenly increased, reaching $2.24 \%$ in a 2014 national survey in the United States [1]. The prevalence of ASD is likely to increase in Japan [2].

Vitamin $\mathrm{D}$ is a secosteroid associated with peripheral calcium homeostasis and nervous system function [3]. Vitamin D exists in two major forms, vitamin D2 from plants and D3 from animals. Both vitamin D2 and D3 are biologically inert and require activation through two hydroxylation processes involving 25-hydrooxylase (CYP2R1) and 1a-hydroxylase (CYP27B1), located in the liver and kidney, respectively [4]. 1, 25-dihydroxyvitamin D (1, 25OHD) is a biologically active metabolite produced by two hydroxylation reaction steps in the nervous system [5]. Vitamin D modulates the central nervous system thorough its receptors which are expressed in neuronal and glia cells in almost all regions of the central nervous system [6].

It has been suggested that vitamin D reduces the risk of ASD. Cohort studies, have shown low neonatal vitamin $\mathrm{D}$ to be a possible risk factor for ASD [7, 8]. Studies have also investigated the association between vitamin $\mathrm{D}$ concentrations during pregnancy and total behavioral and neurodevelopmental problem [9-11]. However, prospective studies have not found an association between 25-hydroxyvitamin D (25OHD) concentration and ASD.

ASD usually appears during the first three years of life [12]. In one case report, Vitamin D supplementation led to significant reduction

\section{Publication History:}

Received: December 13, 2019

Accepted: January 07, 2020

Published: January 09, 2020

\section{Keywords:}

Vitamin D, Autism spectrum disorder, 3-year-old children, Supplementation, $25 \mathrm{OHD}$ in core symptoms of ASD [13]. The present study was designed to investigate the effect of vitamin D3 supplementation corresponding to twice the daily requirement for 9 months on core symptoms of 3-yearold Japanese children with ASD.

\section{Materials and Methods}

\section{Subjects and setting}

Prior to the study, approval was obtained from the ethics committee of Bukkyo University (project registration number in 2018: 7). We enrolled 5 males and 1 female Japanese ASD children aged 3 years. The researchers were present at the child welfare institution (Mukunokien, Kyoto, Japan) where the study was conducted to assure the proper management of safety and confidentiality in the study. The manager of the institution invited parents to participate in the study, and all the children whose participation was requested from January to September in 2019 were enrolled. All subjects took oral vitamin D supplements (Baby D 200: 5.0 $\mu$ g/day of vitamin D3 oil purchased from Morishita Jintan Co., Ltd., Osaka) for 9 months.

*Corresponding Author: Prof. Noboru Hasegawa, Department of Health and Medical Sciences, Ishikawa Prefectural Nursing University, 1-1 Gakuendai, Kahoku, Ishikawa 929-1210, Japan, Tel: +81-76-281-8300, Fax: +81-281-8319; E-mail: hsgwn@ishikawa-nu.ac.jp

Citation: Hasegawa N, Yamada T, Mochizuki M (2020) Vitamin D3 Supplementation Ameliorates Typical Clinical Symptoms in Children with Autism Spectrum Disorder in Japan: A Case Study. Int J Nurs Clin Pract 7: 318. doi: https:// doi.org/10.15344/2394-4978/2020/318

Copyright: (C) 2020 Saleh et al. This is an open-access article distributed under the terms of the Creative Commons Attribution License, which permits unrestricted use, distribution, and reproduction in any medium, provided the original author and source are credited. 
Citation: Hasegawa N, Yamada T, Mochizuki M (2020) Vitamin D3 Supplementation Ameliorates Typical Clinical Symptoms in Children with Autism Spectrum Disorder in Japan: A Case Study. Int J Nurs Clin Pract 7: 318. doi: https://doi.org/10.15344/2394-4978/2020/318

\section{Adaptive function test}

All children were assessed for autism behavior using the Childhood Autism Rating Scale (CARS) [14]. An adaptive behavior scale (Vineland-II) [15] was used to identify communication, daily life, social and motor skills through a semi-structured interview conducted with parent and caregiver. The Short Sensory Profile (SSP) was used to quickly identify children with sensory processing problems from parent reports of sensory behaviors in their child [16].

The tests were performed by skilled occupational therapists.

\section{SerumCa, iPTH and 25OHD}

Blood was collected by venipuncture and serumCa, iPTH and 25OHD concentrations were measured by Kyoto Microbio Laboratory, (Kyoto, Japan).

\section{Statistical analysis}

The differences between before and after intervention with vitamin D3 supplements were evaluated using the Wilcoxon test. A p-value of $<0.05$ was considered to be statistically significant. Analyses were carried out using SPSS 21 for Windows (IBM, Japan).

\section{Results and Discussion}

\section{Study subjects}

Characteristics of the study subjects are shown in Table 1. Age was 3 years for all the children (males, $n=5$ females, $n=1$ ). Ca and iPTH were within the normal range, but $25 \mathrm{OHD}$ was below the sufficient value ( $>=30 \mathrm{ng} / \mathrm{mL})$ (Table 1$)$.

\begin{tabular}{|l|l|}
\hline $\mathrm{Ca}(\mathrm{mg} / \mathrm{dL})$ & $9.71 \pm 0.43$ \\
\hline iPTH $(\mathrm{pg} / \mathrm{mL})$ & $25.0 \pm 8.75$ \\
\hline $25 \mathrm{OHD}(\mathrm{ng} / \mathrm{mL})$ & $22.55 \pm 5.5$ \\
\hline
\end{tabular}

\section{Change in serum 25OHD}

Serum 25OHD was classified as normal ( $>=30 \mathrm{ng} / \mathrm{ml}$ ), insufficient ( $>20$ to 29.9 ), or deficient $(<=20)$. In this study, the level was deficient $(n=2)$ or insufficient $(n=4)$. Nine-month intake of vitamin D3 supplements increased serum $\mathrm{Ca}$ and 25OHD concentration significantly (Figure 1). Serum $\mathrm{Ca}$ and iPTH were within normal range for 9 months. The vitamin $\mathrm{D}$ deficient group decreased from 2 children to 1 (1: became insufficient) and the insufficient group decreased from 4 children to 3 (1: became sufficient). These results suggest that vitamin D3 supplement intake increased serum 25OHD levels.

\section{Adaptive function}

The CARS and SSP scores decreased in all except one child who had originally high 25 -hydroxy vitamin D levels (28 ng/mL) (Figure 2).

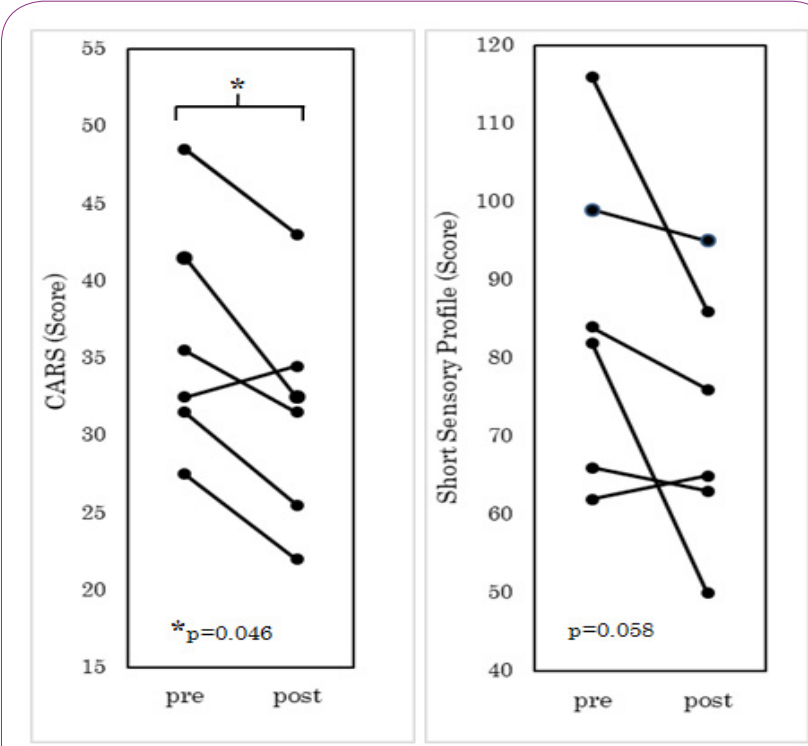

Figure 2: CARS and Short Sensory Profile during intake of vitamin D3.
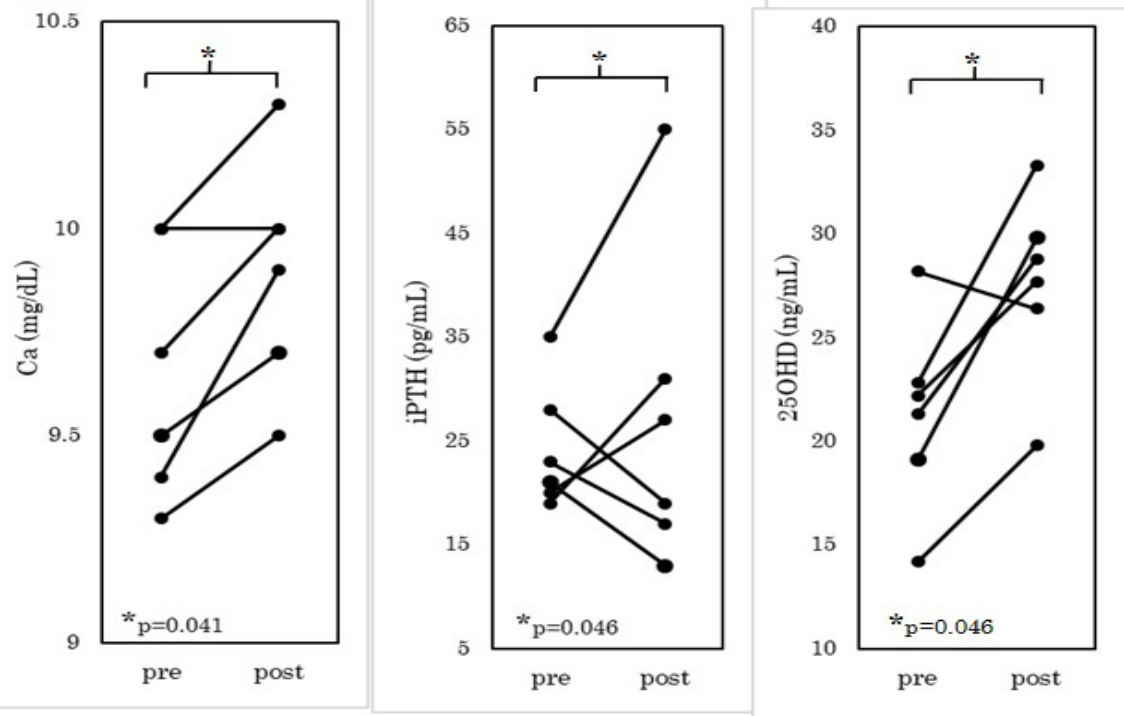

Figure1: SerumCa, iPTH and 25OHD during intake of vitamin D3. 

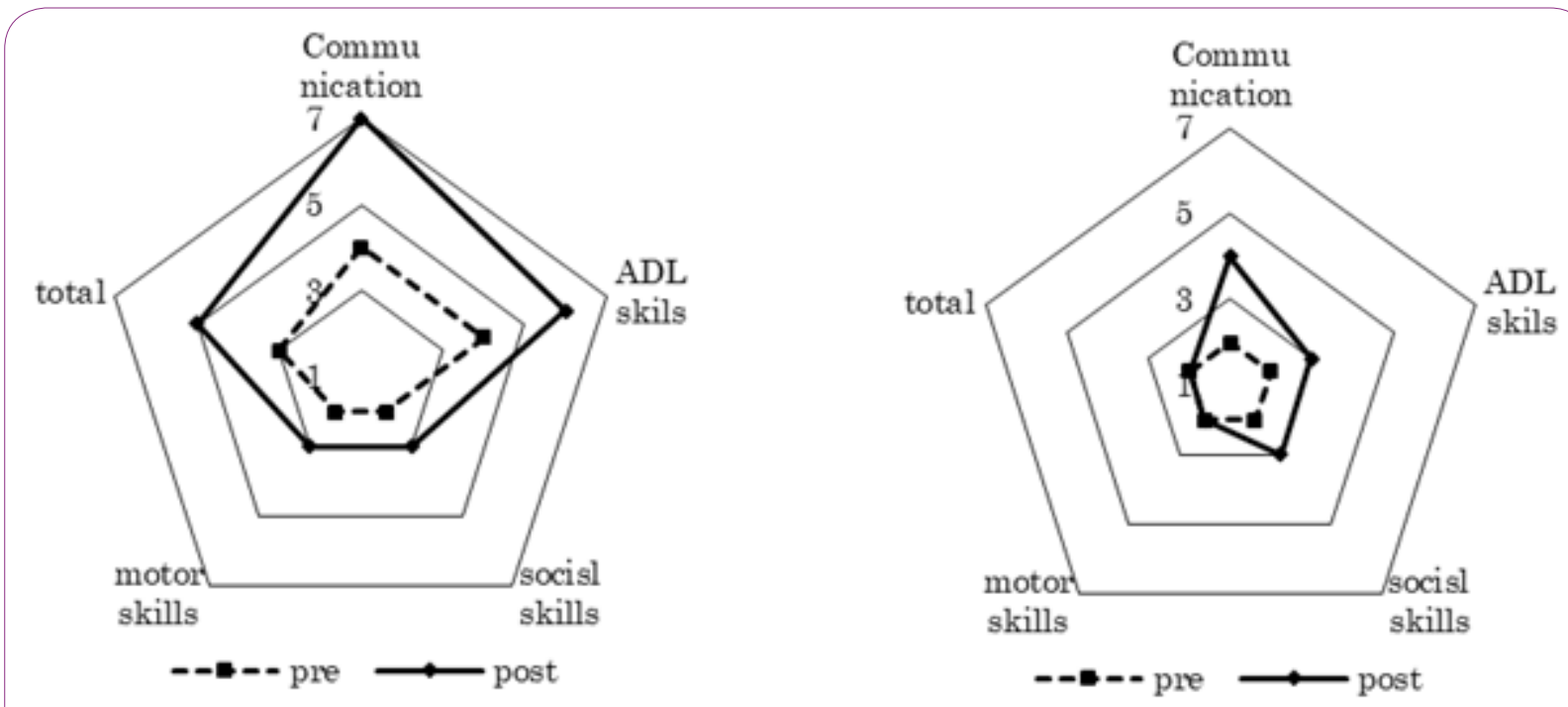

Figure 3: Typical change inclinical symptoms during intake of vitamin D3. The values were shown in stanine.

Among the ASD children in this study, vitamin D administration had a positive effect on "communication skills", "ADL skills", "social skills" or "motor skills" in two children, based on the Vineland-II (Figure 3).

Many epidemiological studies have assessed the relationship between vitamin D and ASD [17]. The majority have examined the relationship between the vitamin $\mathrm{D}$ status of pregnant women and the risk of ASD in their children, and reported the vitamin D status of ASD children. Some studies have found no relationship between vitamin D status and ASD $[18,19]$.

A few studies have reported the effect of vitamin $\mathrm{D}$ supplementation in women during pregnancy and in children with ASD. Vitamin D supplementation at adequate dose during pregnancy reduces the incidence of autism [20]. Administration of vitamin D administration to a vitamin D deficient 32-month-old boy with ASD improved his core symptoms of autism [13]. Among the children in this study, vitamin D supplementation had an ameliorative effect on "communication skills", "ADL skills", "social skills" or "motor skills" associated with the disorder.

Vitamin D is regarded as a hormone that is active not only in regulating blood calcium but also in brain development. Vitamin $\mathrm{D}$ may have a positive effect on serotonin, which affects brain development [21]. The developmental disruption of serotonin signaling may be involved in autism [22]. These results suggest that vitamin $\mathrm{D}$ supplementation may ameliorate clinical symptoms in ASD children.

This is a preliminary study with a very small number subjects, and it was uncontrolled. Further study with larger numbers of subjects is warranted, and could reveal optimal 25OHD levels for ameliorating ASD symptoms and preventing falls in ASD children.

\section{Conclusion}

These findings indicate that vitamin $\mathrm{D}$ supplementation might improve adaptive function.

\section{Author Contributions}

Dr. Hasegawa was responsible for the study conception, design, and analysis, interpretation of data, and drafting of the manuscript.

Ms. Mochizuki was responsible for data acquisition and proof reading of the manuscript, and she participated in the data analysis.

Dr. Yamada was responsible for the data acquisition and proof reading of the manuscript.

\section{Acknowledgements}

The author acknowledges Ms. Chizu Shibuya and Ms. Fumie Fukuda for then kind help.

\section{Competing Interest}

The authors declare that they have no competing interest.

\section{References}

1. Zablotsky B, Black LI, Maenner MJ, Schieve LA, Blumberg SJ, et al. (2015) Estimated prevalence of autism and other developmental disabilities following questionnaire changes in the 2014 National Health Interview Survey. Natl Health Stat Report 13: 1-20.

2. Honda $H$, Shimizu $Y$, Imai $M$, Nitto $Y$ (2005) Cumulative incidence of childhood autism: a total population study of better accuracy and precision. Dev Med Child Neurol 47: 10-18.

3. DeLuca GC, Kimball SM, Kolasinski J, Ramagopalan SV, Ebers GC, et al. (2013) Review: the role of vitamin D in nervous system health and disease. Neuropathol Appl Neurobiol 39: 458-484.

4. Sarfraz Z (2015) Vitamin D: A Hormone. In: Sarfraz Z (Ed) Power of Vitamin D (3rd edition), CreateSpace Independent Publishing Platform, USA, pp. 1819

5. Garcion E, Wion-Barbot N, Montero-Menei CN, Berger F, Wion D, et al. (2002) Newclues about vitamin D functions in the nervous system. Trends Endocrinol Metab 13: 100-105.

6. Eyles DW, Smith S, Kinobe R, Hewison M, McGrath JJ, et al. (2005) Distribution of the vitamin $D$ receptor and 1 alpha-hydroxylase in human brain. J Chem Neuroanat 29: 21-30. 
Citation: Hasegawa N, Yamada T, Mochizuki M (2020) Vitamin D3 Supplementation Ameliorates Typical Clinical Symptoms in Children with Autism Spectrum Disorder in Japan: A Case Study. Int J Nurs Clin Pract 7: 318. doi: https://doi.org/10.15344/2394-4978/2020/318

7. Fernell E, Bejerot S, Westerlund J, Miniscalco C, Simila H, et al. (2015) Autism spectrum disorder and low vitamin $\mathrm{D}$ at birth: a sibling control study. Molecular Autism 6: 3-9.

8. Schmidt RJ, Niu Q, Eyles DW, Hansen RL, Losif AM, et al. (2019) Neonatal vitamin $\mathrm{D}$ status in relation to autism spectrum disorder and developmental delay in the CHARGE case-control study. Autism Res 12: 976-988.

9. Vinkhuyzen AAE, Eyles DW, Burne THJ, Blanken LME, Kruithof CJ, et al. (2018) Gestational vitamin D deficiency and autism-related traits: the Generation R Study. Molecular Psychiatry 23: 240-246

10. Magnusson C, Lundberg M, Lee BK, Rai D, Karlsson H, et al. (2016) Maternal vitamin $D$ deficiency and the risk of autism spectrum disorders: populationbased study. BJ Psych Open 2: 170-172.

11. Darling AL, Rayman MP, Steer CD, Golding J, Lanham-New SA, et al. (2017) Association between maternal vitamin D status in pregnancy and neurodevelopmental outcomes in childhood: results from the Avon Longitudinal Study of Parents and Children (ALSPAC). Br J of Nutr 117 1682-1692.

12. New Zealand Guidelines Group (2010) What does ASD look like? In: New Zealand Guidelines Group (Ed) A resource to help identify autism spectrum disorder. New Zealand.

13. Jia F, Wang B, Shan L, Xu Z, Staal WG, et al. (2015) Core symptoms of autism improved after vitamin D supplementation. Pediatrics 135: e196-e198.

14. Schopler E, Reichler RJ, DeVellis RF, Daly K (1980) Toward objective classification of childhood autism: Childhood Autism Rating Scale (CARS). J Autism Dev Disord 10: 91-103.

15. Kanne SM, Gerber AJ, Quirmbach LM, Sparrow SS, Cicchetti DV, et al. (2011) The role of adaptive behavior in autism spectrum disorders: implication for functional outcome. J Autism Dev Disord 41: 1007-1018.

16. Kientz MA, Dunn W (1997) A comparison of the performance of children with and without autism on the sensory profile. Am J Occup Ther 51: 530537

17. Mazahery H, Camargo jr CA, Conlon C, Beck KL, Kruger MC, et al. (2016) Vitamin $D$ and autism spectrum disorder: a literature review. Nutrients 8 : 236-271.

18. Mónica LV, Jordi S, Nerea L, Llúcia G, Cristina RD, et al. (2019) Maternal circulating vitamin D3 levels during pregnancy and behavior across childhood. Sci Rep 9: 14792-14799.

19. Windham GC, Pearl M, Anderson MC, Poon V, Eyles D, et al. (2019) Newborn vitamin $D$ levels in relation to autism spectrum disorders and intellectual disability: A case-control study in California. Autism Res 12: 989-998.

20. Stubbs G, Henley K, Green J (2016) Autism: Will vitamin D supplementation during pregnancy and early childhood reduce the recurrence rate of autism in newborn siblings? Med Hypotheses 88: 74-78.

21. Patric RP, Ames BN (2014) Vitamin D hormone regulates serotonin synthesis. Part 1: relevance for autism. FASEB J 28: 2398-2413.

22. Yang CJ, Tan HP, Du YJ (2014) The developmental disruptions of serotonin signaling may be involved in autism during early brain development. Neuroscience 267: 1-10. 